\title{
Beck Depression Inventory as a Predictor of Long-term Outcome Among Patients Admitted to the Breast Cancer Diagnosis Unit: A 25-year Cohort Study in Finland
}

\author{
MATTI ESKELINEN $^{1 *}$, RIIKA KORHONEN $^{1 *}$, TUOMAS SELANDER $^{2}$ and PAULA OLLONEN ${ }^{3}$ \\ Departments of ${ }^{1}$ Surgery and ${ }^{3}$ Psychiatry, and ${ }^{2}$ Science Service Center, \\ Kuopio University Hospital and \\ School of Medicine, University of Eastern Finland, Kuopio Campus, Kuopio, Finland
}

\begin{abstract}
Aim: The Beck Depression Inventory (BDI) is one of the most widely used instruments for measuring the severity of depression. However, there has been no prospective study to investigate the long-term outcome in patients admitted to Breast Cancer Diagnosis Units. Patients and Methods: In the Kuopio Breast Cancer Study, women with breast symptoms were evaluated for total BDI score before any diagnostic procedures were carried out. The relapse-free survival (RFS) was calculated from the time of diagnosis to the time of first relapse including local relapse, contralateral breast cancer $(B C)$ or metastatic disease. The overall survival (OS) was assessed as the time from the date of diagnosis to the date of last follow-up or death of the patient. The effect of the BDI on the RFS and on the OS were calculated by the Kaplan-Meier survival analysis and the difference between the groups was assessed by the log-rank test. The RFS and OS was estimated for the study groups with a low BDI score $(<8)$ versus those with a high BDI score $(\geq 8)$. The end-point of our study was to determine differences in long-term outcome and in BDI score in individuals with $B C$, benign breast disease (BBD) and in healthy study subjects (HSS). Results: In the Cox proportional hazard model, the total BDI score significantly predicted the 25-year $R F S$ and $O S$ in the HSS, BBD and BC groups combined (Hazard Ratio=1.87, $p=0.039$; Hazard Ratio=1.98, $p=0.048$,
\end{abstract}

This article is freely accessible online.

*These Authors contributed equally to this study.

Correspondence to: Matti Eskelinen, MD, Ph.D., School of Medicine, University of Eastern Finland, P.O. Box 100, FI-70029 KYS, Finland. Tel: +358 17173311, Fax: +358 17172611, GSM: +358 400969444, e-mail: matti.eskelinen@kuh.fi

Key Words: BDI, breast disease, breast cancer, 25-year outcome. respectively), and in the Kaplan-Meier survival analysis with the log-rank test, the total BDI score predicted the 25-year RFS and $O S$ in the HSS, BBD and BC groups combined ( $p=0.043 ; p=0.036$, respectively). Conclusion: The BDI is a significant predictor of long-term outcome among patients admitted to the Breast Cancer Diagnosis Unit in Finland.

Breast cancer (BC) is the most common cancer in females, with approximately 1.7 million new BC cases diagnosed globally per year. In addition, over a half million women die every year from BC. In Finland 5008 women were diagnosed with BC in 2014 and 5-year and 20-year survival was reported to be $90 \%$ and $62 \%$, respectively $(1,2)$. Many patients with $\mathrm{BC}$ experience recurrence and therefore it is of great importance to indentify predictive factors to find the most effective treatment for each patient.

The Beck Depression Inventory (BDI) has become one of the most widely used psychometric methods detecting depression in normal populations and in different psychiatric patient cohorts (3). It has been translated into multiple languages including Arabian, Chinese, Japanese and Persian (4). Earlier, we assessed the psychometric tools BDI, Montgomery-Asberg depression rating scale and hopelessness/helplessness in healthy study subjects (HSS), benign breast disease (BBD) and BC groups and the results indicated a highly significant agreement between different psychometric inventories (5-9).

Because BC is a hormonally responsive neoplasm with great psychological impact, it is the tumour type most extensively investigated for possible psychological variables associated with risk and survival (10). Hormonal factors, such as early age at menarche, later age at menopause, later age at first full-term pregnancy and hormone replacement therapy, are known to be the main risk factors for sporadic BC (1117). In addition, life-style factors, such as obesity, smoking, alcohol consumption and lack of physical activity, appear to contribute to an increased risk for this malignancy, although the results concerning such factors are inconsistent (11-17). 
Table I. Characteristics of the study participants. Results are shown for patients with breast cancer (BC), those with benign breast disease (BBD) and for the healthy study participants (HSS).

\begin{tabular}{|c|c|c|c|c|}
\hline Variable & HSS $(n=28)$ & $\operatorname{BBD}(\mathrm{n}=53)$ & $\mathrm{BC}(\mathrm{n}=34)$ & $p$-Value \\
\hline Age (mean, years & 45.7 & 47.6 & 51.6 & 0.12 \\
\hline Height (mean), $\mathrm{cm}$ & 160.8 & 162.3 & 164.4 & 0.75 \\
\hline Body weight (mean), $\mathrm{kg}$ & 68.3 & 67.8 & 72.5 & 0.25 \\
\hline Age at menarche (mean), years & 13.4 & 13.4 & 13.4 & 0.99 \\
\hline Age at birth of I child (mean), years & 25.0 & 25.0 & 25.2 & 0.92 \\
\hline Age at menopause (mean), years & 50.0 & 48.9 & 47.9 & 0.53 \\
\hline No. of children (mean) & 2.5 & 2.4 & 2.6 & 0.27 \\
\hline Parous, n (\%) & $23(82 \%)$ & $44(83 \%)$ & $31(91 \%)$ & 0.50 \\
\hline Breast feeding (mean), months & 3.9 & 3.4 & 3.6 & 0.77 \\
\hline Use of oral contraceptives, $\mathrm{n}(\%)$ & $18(64 \%)$ & $25(47 \%)$ & $13(38 \%)$ & 0.12 \\
\hline HRT, n (\%) & $14(50 \%)$ & $36(68 \%)$ & $27(79 \%)$ & 0.44 \\
\hline Premenopausal, n (\%) & $18(64 \%)$ & $28(53 \%)$ & $13(38 \%)$ & 0.10 \\
\hline Postmenopausal, n (\%) & $10(36 \%)$ & $25(47 \%)$ & $21(62 \%)$ & 0.12 \\
\hline History of previous $\mathrm{BBD}, \mathrm{n}(\%)$ & $10(36 \%)$ & $22(42 \%)$ & $18(53 \%)$ & 0.37 \\
\hline Family history of $\mathrm{BC}, \mathrm{n}(\%)$ & $5(18 \%)$ & $5(9 \%)$ & $1(3 \%)$ & 0.21 \\
\hline Use of alcohol, n (\%) & $13(46 \%)$ & $31(58 \%)$ & $21(62 \%)$ & 0.44 \\
\hline Smoking, n (\%) & $10(36 \%)$ & $21(40 \%)$ & $15(44 \%)$ & 0.80 \\
\hline BDI (mean score) & 7.8 & 8.5 & 8.9 & 0.70 \\
\hline
\end{tabular}

HRT, Use of hormonal replacement therapy; BDI: Beck Depression Inventory.

Psychological factors, such as stressful and adverse life events, are widely thought to play a role in the aetiology of BC (18-39). There has been no prospective study to investigate the predictive value of the BDI in long-term outcome among patients admitted to the Breast Cancer Diagnosis Unit. Therefore, we carried out a prospective study to examine the association between BDI, and 25-year relapse-free (RFS) and overall (OS) survival in HSS, and patients with BBD and $\mathrm{BC}$ in a cohort in Finland.

\section{Patients and Methods}

The Kuopio BC Study was a multidisciplinary cooperative project conducted by different departments of the University of Kuopio and Kuopio University Hospital, and included all women who were referred to the hospital for breast examination between April 1990 and December 1995. The Kuopio BC Study followed the protocol of the International Collaborative Study of Breast and Colorectal Cancer coordinated by the European Institute of Oncology in Milan, and was initiated as a SEARCH program of the International Agency for Research on Cancer. The collaborative study is based on the assumption that $\mathrm{BC}$ and colorectal cancer may have common risk factors. Study centres for the BC study are situated in Canada, Finland, Greece, Ireland, Italy, Russia, Slovakia, Spain and Switzerland (40). The study participants showed BC symptoms (a lump in the breast or in the axilla, pain in the breast, bleeding from the nipple, nipple discharge or skin dimpling), or an abnormality of the breast and the indications for referral in this study were in line with our previous investigations in a BC Diagnostic Unit in Finland $(41,42)$.

This prospective case-control study was approved by the Kuopio University Hospital Board on Research Ethics (approval number $14 / 12 / 1989$ ) and was conducted in accordance with the Declaration of Helsinki. All study participants gave their written informed consent to participate in this study (43). One hundred and fifteen women participated and were interviewed (to determine the level of emotional depression) by a psychiatrist (P.O.) before any diagnostic procedures, so neither the interviewer nor the patient knew the diagnosis at the time of the interview. The interviews were recorded and the ratings were completed before the final diagnosis. The clinical examination, mammography and biopsy showed BC in $34(29.6 \%)$ patients, BBD in $53(46.1 \%)$ patients and $28(23.4 \%)$ HSS (Table I).

Beck Depression Inventory (BDI). The women completed the 21item BDI; the items of BDI contain four statements each, and describe the intensity of a particular depressive symptom (44-46). The total BDI score was rated as follows: grade I, score 0-3 ( $n=39)$, no depression; grade II, score 4-7 ( $\mathrm{n}=22)$, little depression; grade III, score 8-11 $(n=22)$, mild depression; grade IV, score 12-15 $(n=16)$, moderate depression and grade V, score 16-30 $(n=16)$, severe depression. In the present study, the total BDI score was used as a continuous variable with a cut-off of 8 for the total BDI score.

Statistical analysis. Significance of the results was calculated with the SPSS/PC statistical package (SPSS Inc., Chicago, IL, USA). Correlations and differences between the study groups were measured with the two-sided chi-square test and non-parametric Kruskal-Wallis variance analyses. The data on RFS and OS were collected and inspected from Kuopio University Hospital registry. The RFS was calculated from the time of diagnosis to the time of first relapse including the local relapse, the contralateral $\mathrm{BC}$ or the metastatic disease or the death. The OS was assessed as the time from the date of diagnosis to the date of last follow-up or death of the patient. The effect of the BDI on the RFS and on the OS were calculated by the Kaplan-Meier survival analysis and the difference between the groups was assessed by the log-rank test. The RFS and 

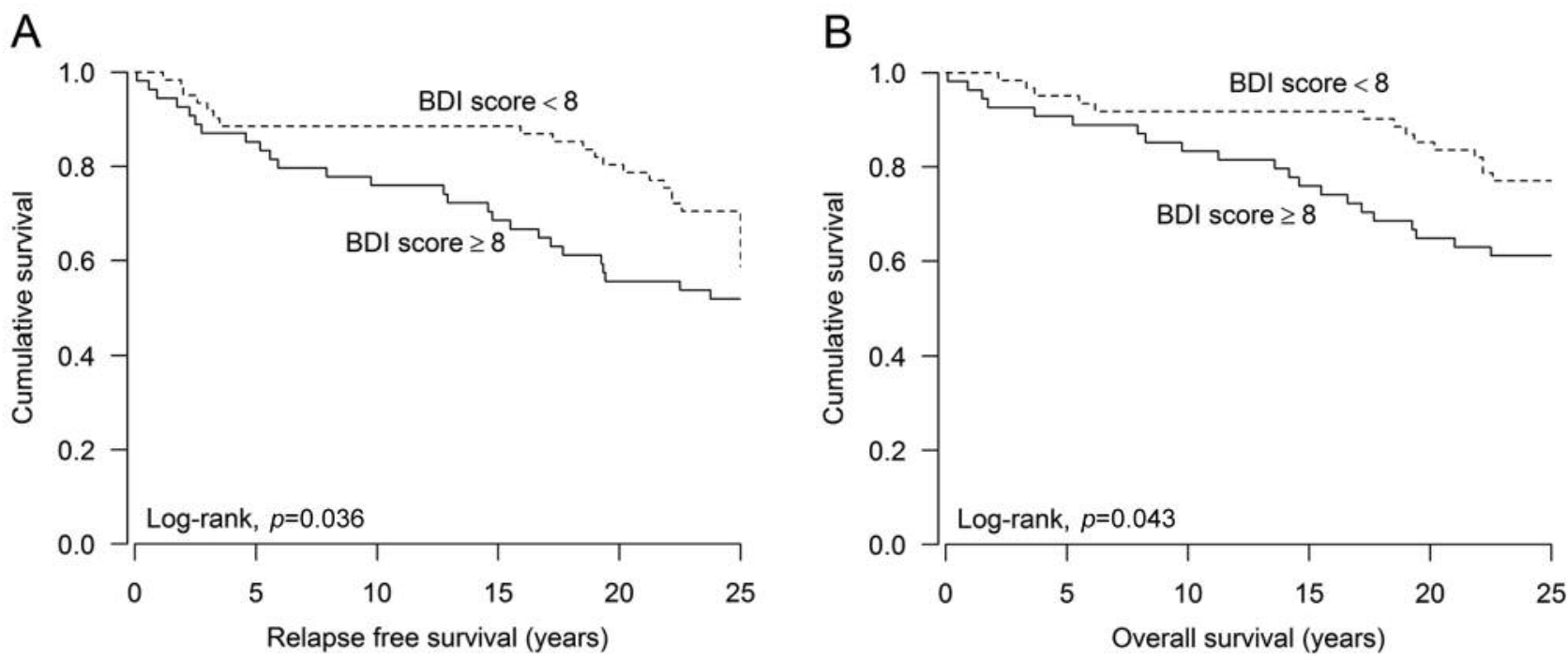

Figure 1. Kaplan-Meier survival curves for relapse-free (RFS) (1A) and overall $(O S)$ survival (1B) for patients with breast cancer (BC), those with benign breast disease $(B B D)$ and for the healthy study participants (HSS) groups combined $(n=115)$ according to total Beck Depression Inventory (BDI) score. The total BDI score was a continuous variable for the study patients. The BDI score had a statistically significant effect on both RFS $(p=0.036)$ and $O S(p=0.036)$ by the log-rank test.

OS was estimated for the groups with a low BDI score $(<8)$ versus groups with a high BDI score $(\geq 8)$. The $p$-values and the hazard ratios (HRs) and their 95\% confidence intervals (CI) were calculated from the Cox proportional hazard models. $p$-Values of 0.05 or less were considered to be statistically significant.

\section{Results}

Although the patients in the BC group were older than those in the BBD and HSS groups (51.5 versus 47.5 and 45.7 years, respectively), the age difference was not statistically significant $(p=0.12)$. The majority of the patients $(85 / 115$, $74 \%$ ) were married or living in a steady relationship. The groups differed only slightly from each other as to the factors of the reproductive life of the women and the mean BDI score values were quite similar in the HSS, BBD and BC groups $(p=0.0702$, Table I).

In the Kaplan-Meier survival analysis of the difference between the groups assessed by the log-rank test showed a low $(<8)$ total BDI score to be a statistically significant favourable predictor of RFS (log-rank $p=0.36$, Figure 1A) and OS (the log-rank $p=0.43$, Figure $1 \mathrm{~B}$ ). In the Cox regression analysis, a low $(<8)$ total BDI score was a statistically significant favourable predictor of the RFS $(\mathrm{HR}=1.87,95 \% \mathrm{CI}=1.03-3.38, p=0.039$, Table II $)$ and the OS ( $\mathrm{HR}=1.98,95 \% \mathrm{CI}=1.00-3.90, p=0.048$, Table III $)$ in the HSS, BBD and BC groups combined. A similar although statistically insignificant pattern was seen in the HSS and the BBD groups (Table II). The 25-year RFS rate in the group with a low total BDI score $(<8)$ versus those with a high total
Table II. Analysis of 25-year relapse-free survival (RFS) for the healthy study subjects (HSS) ( $n=28)$, benign breast disease (BBD) ( $n=53)$ and breast cancer $(B C)(n=34)$ groups and for the study groups combined according to total Beck Depression Inventory (BDI) score. The p-values and hazard ratios (HRs) and their 95\% confidence intervals (CI) were calculated from the Cox proportional hazard models.

\begin{tabular}{|c|c|c|c|c|c|}
\hline \multirow[b]{2}{*}{ Group } & \multicolumn{2}{|c|}{ RFS (\%) } & \multirow[b]{2}{*}{ HR } & \multirow[b]{2}{*}{$95 \% \mathrm{CI}$} & \multirow[b]{2}{*}{$p$-Value } \\
\hline & $\mathrm{BDI}<8$ & $\mathrm{BDI} \geq 8$ & & & \\
\hline All & 31.1 & 48.1 & 1.87 & $1.03-3.38$ & 0.039 \\
\hline HSS & 36.8 & 20.0 & 0.53 & $0.11-2.56$ & 0.430 \\
\hline BBD & 17.9 & 33.3 & 2.08 & $0.68-6.36$ & 0.199 \\
\hline $\mathrm{BC}$ & 50.0 & 80.0 & 2.17 & $0.88-5.36$ & 0.092 \\
\hline
\end{tabular}

Table III. Analysis of 25-year overall survival (OS) for the healthy study subjects (HSS) $(n=28)$, benign breast disease $(B B D)(n=53)$ and breast cancer $(B C)(n=34)$ groups and for the study groups combined according to total Beck Depression Inventory (BDI) score. The p-values and hazard ratios (HRs) and their 95\% confidence intervals (CI) were calculated from the Cox proportional hazard models.

\begin{tabular}{lccccc}
\hline Group & $\begin{array}{c}\text { OS(\%) } \\
\text { BDI }<8\end{array}$ & $\begin{array}{l}\text { OS(\%) } \\
\text { BDI } \geq 8\end{array}$ & HR & $95 \%$ CI & $p$-Value \\
\hline All & 77.1 & 61.1 & 1.98 & $1.00-3.90$ & 0.048 \\
HSS & 84.2 & 80.0 & 1.34 & $0.22-7.99$ & 0.752 \\
BBD & 85.7 & 79.2 & 1.59 & $0.43-5.91$ & 0.492 \\
BC & 50.0 & 30.0 & 1.67 & $0.67-4.16$ & 0.273 \\
\hline
\end{tabular}


BDI score ( $\geq 8)$ differed significantly ( $31.1 \%$ versus $48.1 \%$, respectively, Table II) and in the 25 -year OS rate $(77.1 \%$ versus $61.1 \%$, respectively, Table III).

\section{Discussion}

The BDI, created by Aaron Beck, is a 21-question selfreport inventory and marked a shift among health professionals, who had until then viewed depression from a Freudian psychodynamic perspective, instead of it being linked to the patient's own thoughts and cognitions. The BDI variables are based on Beck's records of the symptoms and signs of depressed patients in psychotherapy (44-46). A group of such symptoms and signs that were specific for the depressed patients were chosen for the BDI rating scale. There are three versions of the BDI: the original BDI, first published in 1961, then later revised in 1978 as BDI-1A, and the BDI-II, published in 1996. The current BDI version, the BDI-II, is designed for individuals aged 13 years and over, and is composed of items relating to symptoms of depression such as hopelessness and irritability, cognitions such as guilt or feelings of being punished, as well as physical symptoms such as fatigue, weight loss, and lack of interest in sex $(47,48)$. The BDI was originally developed to provide a quantitative assessment of the intensity of depression. Because it is designed to reflect the depth of depression, it can monitor changes over time and provide an objective measure for judging improvement and the effectiveness or otherwise of treatment methods. The BDI is widely used as an assessment tool by health care professionals and researchers in a variety of settings.

The BDI suffers from the same bias as other self-report psychometric questionnaires, in that scores can be easily minimized or exaggerated by the test subject. Like all inventories, the way the questionnaire is administered can have an effect on the final score. If a test subject is asked to fill-out the questionnaire in front of other people in a clinical environment, for instance, social expectations have been shown to elicit a different response compared to questionnaire administration via a postal survey (49).

In study participants with concomitant physical illness, the BDI's reliance on physical symptoms such as fatigue may artificially inflate scores due to symptoms of the illness, rather than of depression (50). In an effort to deal with this bias, Beck and colleagues developed a short screening scale consisting of seven items from the BDI-II considered to be independent of physical function (Beck Depression Inventory for Primary Care, BDI-PC). The BDI-PC produces only a binary outcome of depressed or not depressed for study participants above a cutoff score of 4 (51). Although the BDI is designed as a screening tool rather than a diagnostic instrument, the BDI is often used by general practioners to reach a quick diagnosis $(52,53)$.
In the Cox proportional hazard model, the total BDI score significantly predicted the 25-year RFS and OS in the HSS, BBD and BC groups combined, and in the Kaplan-Meier survival analysis with the log-rank test, the total BDI score predicted the 25-year RFS and OS in the HSS, BBD and BC groups combined.

\section{Conclusion}

The BDI is a significant predictor of long-term outcome among patients admitted to the Breast Cancer Diagnosis Unit in Finland.

\section{Conflicts of Interest}

No conflict of interest exists. The Authors alone are responsible for the content and writing of this article.

\section{Acknowledgements}

The support from the Academy of Finland, Paavo Koistinen Foundation, Finnish Cancer Foundation and EVO funds from Kuopio University Hospital are gratefully acknowledged. Our special thanks are due to Ms A.K. Lyytinen, R.N. for help in data collection and Mrs E. Oittinen and Mrs H. Miettinen for excellent technical assistance.

\section{References}

1 Finnish Cancer Registry. Cancer Statistics at www.cancerregistry.fi, 2013.

2 Brenner $\mathrm{H}$ and Hakulinen T: Long-term cancer patient survival achieved by the end of the 20th century: most up-to-date estimates from the nationwide Finnish cancer registry. Brit J Cancer 85: 367-371, 2001.

3 Richter P, J Werner J, Heerlein A, Kraus A and Sauer H: On the validity of the Beck Depression Inventory. A review. Psychopathology 31: 160-188, 1998.

4 Literature available on Psychiatric Assessment Instruments translated in non-English languages: TBDI Section. Victorian Transcultural Psychiatry Unit. Dec 2005 (vtpu.org.au).

5 Eskelinen $\mathrm{M}$ and Ollonen P: Measurement of pessimism: hopelessness scale in healthy study participants, and in patients with benign breast disease and breast cancer: A prospective case-control study in Finland. Anticancer Res 31: 4019-4023, 2011.

6 Eskelinen M, Korhonen R, Selander T and Ollonen P: The Self-Rating Score (SRS) versus the Examiner Rating Score (ERS) in measuring helplessness in healthy individuals and in patients with benign breast disease and breast cancer: a prospective case-control study in Finland. Anticancer Res 34: 5677-5682, 2014.

7 Eskelinen M, Korhonen R, Selander T and Ollonen P: The relation of hopelessness/helplessness versus Beck Depression Inventory (BDI) in healthy individuals and in patients with benign breast disease and breast cancer: a prospective casecontrol study in Finland. Anticancer Res 35: 941-948, 2015. 
8 Eskelinen M, Korhonen R, Selander T and Ollonen P: Agreement between Hopelessness/Helplessness versus Montgomery-Asberg depression rating scale (MADRS) in healthy individuals and in patients with benign breast disease and breast cancer: a prospective case-control study in Finland. Anticancer Res 35: 2215-2222, 2015.

9 Eskelinen M, Korhonen R, Selander T and Ollonen P: Suicidal and pessimistic thoughts versus hopelessness/helplessness in healthy individuals and in patients with benign breast disease and breast cancer: a prospective case-control study in Finland. Anticancer Res 35: 3543-3552, 2015.

10 Key JA, Verkasalo PK and Banks E: Epidemiology of breast cancer. Lancet Oncol 2: 133-140, 2001.

11 Aaltomaa S, Lipponen P, Eskelinen M, Kosma VM, Marin S, Alhava E and Syrjänen K: Hormone receptors as prognostic factors in female breast-cancer. Ann Med 23: 643-648, 1991.

12 Zhu ZR, Agren J, Männistö S, Pietinen P, Eskelinen M, Syrjanen $\mathrm{K}$ and Uusitupa: Fatty-acid composition of breast adipose-tissue in breast cancer patients and in patients with benign breast disease. Nutr Cancer 24: 151-160, 1995.

13 Pietiläinen T, Lipponen P, Aaltomaa S, Eskelinen M, Kosma V$M$ and Syrjänen K: Expression of retinoblastoma gene protein $(\mathrm{RB})$ in breast cancer as related to established prognostic factors and survival. Eur J Cancer 31: 329-333, 1995.

14 Mitrunen K, Kataja V, Eskelinen M, Kosma VM, Kang D, Benhamou S, Vainio H, Uusitupa M and Hirvonen A: Combined COMT and GST genotypes and hormone replacement therapy associated breast cancer risk. Pharmacogenetics 12: 67-72, 2002.

15 Eskelinen M, Norden T, Lindgren A, Wide L, Adami HO and Holmberg L: Preoperative serum levels of follicle-stimulating hormone (FSH) and prognosis in invasive breast cancer. Eur J Surg Oncology 30: 495-500, 2004.

16 Metsola K, Kataja V, Sillanpää P, Siivola P, Heikinheimo L, Eskelinen M, Kosma VM, Uusitupa M and Hirvonen A: XRCC1 and $X P D$ genetic polymorphisms, smoking and breast cancer risk in a Finnish case-control study. Breast Cancer Research 7: R987-997, 2005.

17 Sillanpää P, Hirvonen A, Kataja V, Eskelinen M, Kosma V-M, Uusitupa M, Vainio $\mathrm{H}$ and Mitrunen K: NAT2 slow acetylator genotype as an important modifier of breast cancer risk. Int $\mathrm{J}$ Cancer 114: 579-584, 2005.

18 Chen CC, David AS, Nunnerley H, Michell M, Dawson JL, Berry H, Dobbs J and Fahy T: Adverse life events and breast cancer: case-control study. BMJ 311: 1527-1530, 1995.

19 Roberts FD, Newcomb PA, Trentham-Dietz A and Storer BE: Self-reported stress and risk of breast cancer. Cancer 77: 10891093, 1996.

20 Protheroe D, Turvey K, Horgan K, Benson E, Bowers D and House A: Stressful life events and difficulties and onset of breast cancer: case-control study. BMJ 319: 1027-1030, 1999.

21 Price MA, Tennant CC, Butow PN, Smith RC, Kennedy SJ, Kossoff MB and Dunn SM: The role of psychosocial factors in the development of breast carcinoma: Part II. Life event stressors, social support, defense style, and emotional control and their interactions. Cancer 91: 686-697, 2001.

22 Duijts SFA, Zeegers MPA and VD Borne B: The association between stressful life events and breast cancer risk: a metaanalysis. Int J Cancer 107: 1023-1010, 2003.

23 Ollonen P, Lehtonen J and Eskelinen M: Stressful and adverse life experiences in patients with breast symptoms; a prospective case-control study in Kuopio, Finland. Anticancer Res 25: 531536, 2005.

24 Ollonen P, Lehtonen J and Eskelinen M: Anxiety, depression and the history of psychiatric symptoms in patients with breast disease: a prospective case-control study in Kuopio, Finland. Anticancer Res 25: 2527-2534, 2005.

25 Ollonen P, Lehtonen $\mathrm{J}$ and Eskelinen M: Coping and defending as risk factors for breast cancer in patients with breast disease: a prospective case-control study in Kuopio, Finland. Anticancer Res 25: 4623-4630, 2005.

26 Ollonen P and Eskelinen M: Idealization as risk factor for breast cancer in patients with breast disease: a prospective case-control study in Kuopio, Finland. Anticancer Res 27: 1625-1630, 2007.

27 Eskelinen M and Ollonen P: Psychosocial risk scale (PRS) for breast cancer in patients with breast disease: a prospective case-control study in Kuopio, Finland. Anticancer Res 29: 4765-4770, 2009.

28 Eskelinen $\mathrm{M}$ and Ollonen P: The body image drawing analysis in women with breast disease and breast cancer: anxiety, colour and depression categories. Anticancer Res 30: 683-691, 2010.

29 Eskelinen $\mathrm{M}$ and Ollonen P: Evaluation of women with breast disease using body image drawing analysis. Anticancer Res 30: 2399-2406, 2010.

30 Eskelinen $\mathrm{M}$ and Ollonen P: Life stress due to losses and deficit in childhood and adolescence as breast cancer risk factor: a prospective case-control study in Kuopio, Finland. Anticancer Res 30: 4303-4308, 2010.

31 Eskelinen M and Ollonen P: Life stress and losses and deficit in adulthood as breast cancer risk factor: a prospective case-control study in Kuopio, Finland. In Vivo 24: 899-904, 2010.

32 Eskelinen M and Ollonen P: Beck Depression Inventory (BDI) in patients with breast disease and breast cancer: a prospective case-control study. In Vivo 25: 111-116, 2011.

33 Eskelinen $\mathrm{M}$ and Ollonen P: Forsen Psychological Risk Inventory for breast cancer patients: a prospective case-control study with special reference to the use of psychiatric medications. Anticancer Res 31: 739-744, 2011.

34 Eskelinen M and Ollonen P: Montgomery-Asberg depression rating scale (MADRS) in healthy study participants, in patients with breast disease and breast cancer: a prospective case-control study. Anticancer Res 31: 1065-1069, 2011.

35 Eskelinen $\mathrm{M}$ and Ollonen P: Assessment of general anxiety in patients with breast disease and breast cancer using the Spielberger STAI self evaluation test: a prospective case-control study in Finland. Anticancer Res 31: 1801-1806, 2011.

36 Eskelinen M and Ollonen P: Sifneos Alexithymia Questionnaire in assessment of general alexithymia in patients with breast disease and breast cancer: a prospective case-control study in Finland. Anticancer Res 31: 3101-3106, 2011.

37 Eskelinen $\mathrm{M}$ and Ollonen P: Assessment of 'cancer-prone personality' characteristics in healthy study participants and in patients with breast disease and breast cancer using the Commitment Questionnaire: A prospective case-control study in Finland. Anticancer Res 31: 4013-4017, 2011.

38 Kruk J: Self-reported psychosocial stress and the risk of breast cancer: A case-control study. Stress 15: 162-171, 2012.

39 Mitrunen K, Jourenkova N, Kataja V, Eskelinen M, Kosma VM, Benhamou S, Vainio H, Uusitupa M and Hirvonen A: Steroid metabolism gene $C Y P 17$ polymorphism and the development of breast cancer. Cancer Epidemiol Biomarkers Prev 9: 1343-1348, 2000 . 
40 Boyle P: SEARCH programme of the International Agency for Research on Cancer. Eur J Cancer 26: 547-549, 1990.

41 Eskelinen MJ, Pajarinen P, Collan Y, Pesonen E, Alhava E, Kettunen $\mathrm{K}$ and Nordling S: Relationship between DNA ploidy and survival in patients with primary breast cancer. Br J Surg 76: 830-834, 1989.

42 Eskelinen MJ, Lipponen PK, Collan Y and Syrjänen KJ: The role of nucleolar organizer regions as prognostic factors in breast cancer. Eur J Cancer 27: 989-992, 1991.

43 Mitrunen K, Jourenkova N, Kataja V, Eskelinen M, Kosma VM, Benhamou S, Vainio $H$, Uusitupa $M$ and Hirvonen $A$ : Glutathione-S-transferase M1, M3, P1 and T1 genetic polymorphism and susceptibility to breast cancer. Cancer Epidemiol Biomarkers Prev 10: 229-236, 2001.

44 Beck AT, Ward C, Mendelson M:Beck Depression Inventory (BDI). Arch Gen Psychiatry 4: 561-571, 1961.

45 Beck AT and Beck RW: Screening depressed patients in family practice: a rapid technique. Postgrad Med 52: 81-85, 1972.

46 Beck AT: Depression: Causes and Treatment. Philadelphia, University of Pennsylvania Press, 1972.

47 Beck AT, Steer RA, Ball R and Ranieri W: Comparison of Beck Depression Inventories -IA and -II in psychiatric outpatients. J Personality Assess 67: 588-597, 1996.

48 Beck AT, Steer RA and Brown GK: Manual for the Beck Depression Inventory-II. San Antonio, TX: Psychological Corporation, 1996.
49 Bowling A: Mode of questionnaire administration can have serious effects on data quality. J Public Health 27: 281-291, 2005.

50 Moore MJ, Moore PB and Shaw PJ: Mood disturbances in motor neurone disease. J Neurological Sciences 160: S53-56, 1998.

51 Steer RA, Cavalieri TA, Leonard DM and Beck AT: Use of the Beck Depression Inventory for Primary Care to screen for major depression disorders. Gen Hosp Psychiatry 21: 106-111, 1999.

52 Eskelinen $\mathrm{M}$ and Ollonen P: Contribution of emotional distance and reserve in patient-physician communication in healthy study patients, and in patients with benign breast disease and breast cancer: a prospective case-control study in Finland. Anticancer Res 34: 1269-1274, 2014.

53 Eskelinen M, Korhonen R, Selander T and Ollonen P: Emotional personality/proximity versus emotional authenticity in patientphysician communication in healthy study participants, and in patients with benign breast disease and breast cancer: a prospective case-control study in Finland. Anticancer Res 35: 1627-1634, 2015. 